\title{
Kant y Dios: pruebas, postulados y religión"
}

\author{
Jaime Ricardo Reyes Calderón ${ }^{* *}$
}

Recibido: 19 de noviembre 2014 • Aprobado: 20 de enero 2015

\section{Resumen}

En un contexto postmoderno, en el cual se ha devaluado tanto el poder de la razón como la importancia de los compromisos y deberes éticos, el creyente debe volver los pasos hacia una fundamentación racional y moral de Dios. Este breve y panorámico estudio tiene como objetivo aportar unas líneas de comprensión que permitan acercarnos al concepto de Dios en Kant señalando los argumentos principales en cuatro momentos específicos y fundamentales del desarrollo de su filosofía crítica. Para cumplir con ese cometido se enunciarán las relaciones conceptuales más relevantes alrededor de las significaciones acerca de la naturaleza y Dios, las pruebas de la existencia de Dios, los postulados de la razón práctica y la religión moral.

Palabras clave: Kant, Dios, pruebas, postulados, moral

"Producto de las investigaciones del autor

* Magíster en educación por la Universidad Santo Tomás. Especialista en literatura de la Universidad del Quindío. Licenciado en filosofía y Teólogo de la Pontificia Universidad Javeriana. Doctorando en educación por la UPEL (Venezuela). Exreligioso escolapio, actualmente es profesor asociado de la Universidad Libre de Cúcuta, Colombia. Correo electrónico: jaime. reyes@unilibrecucuta.edu.co 


\title{
Kant and God: proofs, postulates and religion
}

\begin{abstract}
In a postmodern context that has devalued both the power of reason as the importance of the commitments and ethical responsibilities, the believer must return the steps towards a rational and moral foundation of God. This brief and panoramic study aims to provide a few lines of understanding enabling closer to the concept of God in Kant pointing to the development of his critical philosophy major in four specific times and fundamental arguments. To comply with this responsibility shall set forth the most relevant conceptual relations around the meanings about the nature and God, proofs for of God's existence, the postulates of practical reason and the moral religion.
\end{abstract}

Keywords: Kant, God, proofs, postulates, moral

\section{Kant et Dieu: preuves, postulats et religion}

\section{Résumé}

Dans un contexte post moderne, où tant le pouvoir de la raison comme l'importance des engagements et devoirs éthiques s'est dévalué, le croyant doit se retourner vers une justification rationnelle et morale de Dieu. Cette étude brève et panoramique a comme objectif de fournir quelques lignes de compréhension, qui permettent de nous approcher de Dieu en Kant, signalant les arguments principaux à quatre moments spécifiques et fondamentaux du développement de la philosophie critique. Pour arriver à cette fin on énoncera les relations conceptuelles plus pertinentes, autour des significations sur la nature de Dieu, les postulats de la raison pratique et la religion morale.

Mots-clés: Kant, Dieu, preuves, postulats, morale.

\section{Introducción}

Kant fue pietista, educado en grandes exigencias religiosas que forjaron su carácter riguroso, preciso y radical. Hijo de la ilustración, lleva las fronteras de la autonomía racional a lugares que ni él mismo sospechó cuando iniciaba su recorrido filosófico. Da buena muerte a la absolutez del pensamiento metafísico y vacía de contenido los envases infinitos del concepto de Dios, llenándolos ahora con el de 
la subjetividad humana -cognoscente y práctica-, erigida como el mayor punto de articulación de la realidad. Dios se postulará como un ideal que posibilita las perfecciones de la moral. A continuación, esbozamos su concepto de Dios recorriendo cuatro grandes momentos de su producción, enlazando el horizonte de lo teórico, con el de lo práctico y lo religioso en cuatro relaciones que delimitan el concepto de Dios en el desarrollo de su filosofía crítica.

\section{Dios y naturaleza en la etapa precrítica}

Iniciamos nuestro breve recorrido con Historia natural y teoría de los cielos, (1755), que representa una exposición rigurosa y amena acerca de la cosmología, fundada en las informaciones de científicos como Newton, Tycho Brache, Huygens, Herschel, Laplace y otros. En este primer momento de la obra kantiana mantiene una polémica con Newton, aunque su posición aún permite la comprensión de Dios mediante comprobaciones teóricas de corte tradicional. No ha decantado todavía los principios de la filosofía crítica.

Kant estableció allí que, más allá del sentido de los órdenes terrestres, solares y cósmicos, en relación con un Ser Supremo, el universo infinito opera como "una realidad ordenada de una manera puramente mecánica, sin requerir ni de causas finales ni de intervenciones ocasionalistas de Dios en la marcha del mundo" (Pannenberg, 2001, p. 204). Con ello aparta cualquier tentación de providencialismo y también se aleja de la percepción newtoniana, que veía en el espacio y el tiempo "el sensorium Dei, es decir, el medio por el cual Dios está presente a cada una de sus criaturas en su lugar respectivo" (p. 213). Espacio y tiempo que serían los canales por los que Dios desplegó su actividad creadora. Kant da a la naturaleza el carácter de composición progresiva, compleja, a través de la eternidad y del infinito, pero a la materia de esos universos le atribuye como razón creadora, a Dios; de suerte que la perfección de la mecánica natural es demostración de la acción creadora:

Todo lo que entre sí se relaciona en una mutua armonía, ha de estar ligado entre sí en un solo ser del cual depende en su totalidad. Por consiguiente, existe un ser de todos los seres, una razón infinita y una sabiduría autónoma de donde hasta en su sola posibilidad la naturaleza deriva su origen en toda la esencia de las determinaciones. Ahora ya no se puede negar la capacidad de la naturaleza, porque ello menoscabaría la existencia de un Ser Supremo; cuanto más perfecta sea en sus desarrollos, cuanto mejor conduzca sus leyes generales hacia el orden y 
la coincidencia, tanto mejor prueba es ella de la deidad de la cual deriva estas condiciones. (Kant, 1946, p. 147)

Muy cerca a Spinoza, la mecánica de la naturaleza expresa la dependencia del mundo respecto a Dios, pero al tiempo afirma su radical diferencia. El medioevo y, más contemporáneo, Leibniz, consideraban que de la materia preexistente, Dios daba forma y orientación como el famoso demiurgo, en una perspectiva muy platónica. Criticando tal percepción platonizante de Leibniz, para luego proponer Kant, que la materia fue ordenada por Dios desde unas ideas preexistentes; permitía desterrar a Dios de la creación y caer en un ateísmo sutil, pues Dios no sería el autor de la materia, sino solamente un moldeador, un ensamblador de relaciones un tanto artificiales. Y Kant en este punto de su reflexión define a Dios no como artífice, sino como creador, como generador de la realidad. Tras el acto creador, la materia, la naturaleza, lo mundano, gozaría de una perfecta autonomía en cuya contingencia se manifestaba la libertad del acto creador divino. Las leyes generales, la concordancia entre las fuerzas de la naturaleza, antes que disputar a Dios el gobierno de la naturaleza, hablan del origen del universo en un "único y supremo entendimiento" (Kant citado por Pannenberg, p. 205).

\section{Las pruebas de la existencia de Dios, Crítica de la razón pura}

En la Crítica de la razón pura (1781), Kant para responder la gran pregunta programática de ¿qué podemos conocer?, desarrolla un discurso epistemológico cuya base es el uso de la razón teórica desde el ejercicio experiencial y matematizante de la física newtoniana. Examina la posibilidad del conocimiento, las posibilidades de formulación de leyes científicas (juicios sintéticos a priori). En ese estudio, enfoca al final el objeto Dios, (infinito, supremo, totalizador, ens realissimum) y desarrolla la posibilidad de que, como objeto de la metafísica sea un elemento de conocer científico.

Kant enfrenta entonces los supuestos de validación del conocimiento de lo que él denominará la "teología trascendental"; es decir, aquella disciplina que pretendía conocer a Dios, a partir un discurso conceptual donde "lo propio de los argumentos que desarrolla es articularse con solos y los mismos conceptos dichos" (Gómez, 1983, p. 81). Acomete entonces en la Dialéctica trascendental, (c. III, El ideal de la razón pura, secciones cuarta a séptima), las tres pruebas que 
tradicionalmente sustentaban el conocimiento de Dios: prueba ontológica, prueba cosmológica y prueba fisicoteológica, con el fin de demostrar "que la razón no consigue ningún resultado positivo, ni por un camino (el empírico), ni por el otro (el trascendental) y que en vano extiende sus alas, para rebasar el mundo sensible con el poder de la mera especulación" (Kant, 2000, p. 499).

La prueba ontológica se podría enunciar así: Dios es el ser absolutamente perfecto. Su existencia es completamente necesaria dado que, si no existiera, no sería infinitamente perfecto. Es decir, como Dios es infinitamente perfecto, Dios existe. Esta prueba es deudora de San Anselmo de Canterbury y su recordado "Proslogion":

Por tanto, el insensato debe admitir que existe al menos en su entendimiento algo mayor que lo cual nada puede ser pensado [...] Si existiese sólo en el entendimiento, se podría pensar que existiese también en la realidad, lo cual es mayor. [...] Existe, pues, sin género de duda, algo mayor que lo cual no cabe pensar nada, y esto tanto en el entendimiento como en la realidad [...] Puesto que no hay nada mayor que tú, ningún lugar o tiempo te constriñe. (De Canterbury, 1998, pp. 12-32)

El argumento de San Anselmo sería revisado y remozado por Descartes y Leibniz. Kant critica entonces, que resulta imposible hallar la existencia de un objeto por el simple análisis de su concepto. "Como la existencia entra de modo necesario en el objeto de ese concepto - es decir, si ponemos esa cosa como dada (existente)-, quedará puesta su existencia de modo igualmente necesario, este ser será, a su vez, absolutamente necesario [...]" (Kant, 2000, p. 501). La existencia es de un orden distinto a la esencia, que en Dios constaría de un predicado infinito, imposible de percibir sensiblemente. Todo juicio de existencia es sintético, es decir, exige un tratamiento experiencial, no basta con que el objeto esté analíticamente contenido en el concepto.

De otra parte, si afirmáramos el juicio contrario "Dios no existe", que suprime por igual sujeto y predicado, encontraríamos que suprimiendo la cosa predicada se suprime entonces su posibilidad, lo cual es contradictorio. Así, la existencia se ha calificado desde lo lógico como posibilidad y ello es profundamente contradictorio, dado que algo posible no necesariamente es real. La existencia requiere de un juicio sintético y no puede confundirse con la enunciación lógica, que solo puede surgir como posibilidad. Entonces, ante el objeto Dios, se pueden predicar contradicciones, pues no es un objeto que pueda ser conocido. Se puede pensar a Dios como ser perfecto, pero aún no se determina si existe o no. La prueba ontológica se equivoca al intentar dar un salto, de lo lógico a lo real, de 
lo meramente verbal e imaginativo, a lo experiencial (Verneaux, 1977). Se puede pensar, pero ello no es legítimo ni real al contrastarse con la experiencia. Cierra Kant afirmando:

Todo el esfuerzo y el trabajo invertidos en la conocida prueba ontológica (cartesiana) de la existencia de un ser superior a partir de conceptos son, pues, inútiles [...]. La pretensión de extraer de una idea puramente arbitraria la existencia del objeto correspondiente a esa misma idea ha sido algo totalmente antinatural, una simple innovación del ingenio académico. (Kant, 2000, p. 506)

La prueba cosmológica, presente en Leibniz y en la tercera vía de Santo Tomás (Contingencia) enuncia que si algo existe (concreto, contingente), tiene que existir un Ser absolutamente necesario. Recuperando la reflexión original del Doctor Angélico en la Suma de Teología, primera parte, cuestión segunda, artículo III, recordamos que:

La tercera es la que se deduce a partir de lo posible y de lo necesario. Y dice: Encontramos que las cosas pueden existir o no existir, pues pueden ser producidas o destruidas, y consecuentemente es posible que existan o que no existan. [...] Luego no todos los seres son sólo posibilidad; sino que es preciso algún ser necesario. Todo ser necesario encuentra su necesidad en otro, o no la tiene. Por otra parte, no es posible que en los seres necesarios se busque la causa de su necesidad llevando este proceder indefinidamente, como quedó probado al tratar las causas eficientes (núm. 2). Por lo tanto, es preciso admitir algo que sea absolutamente necesario, cuya causa de su necesidad no esté en otro, sino que él sea causa de la necesidad de los demás. Todos le dicen Dios. (De Aquino, 2001, p. 112)

Por el Aquinate se entiende que en la cadena de relaciones de los seres, todo ser contingente ha sido causado antes por otro ser contingente. Entonces, al remontarse al origen de esa cadena de generaciones, debe existir un ser necesario, incausado, razón del inicio de todos los seres contingentes.

La primera diferencia de la prueba cosmológica respecto a la prueba ontológica tiene que ver con una cierta positividad, que permite criticarla bajo una actitud más indulgente, probablemente por la cercanía al mecanismo de experimentar espacio-temporalmente, el objeto investigado, asociando el devenir natural al encadenamiento de causas contingentes que pueden impulsar la configuración de juicios sintéticos a priori, es decir: científicos. La prueba cosmológica, 
reconoce Kant, tiene un fundamento un tanto más natural. Por ello, al ser considerada por el entendimiento común y también por el especulativo, gana mayor convicción. La prueba cosmológica será entonces la que trace las líneas esenciales para la formulación de una teología natural. Tales líneas, opina el filósofo, se han seguido siempre y se seguirán aún en el futuro. Pero esta cercanía a lo racional, es también apariencia, y termina estando cargada de "tantos principios sofísticos" que la "razón especulativa parece haber desplegado todo su arte dialéctico para producir la mayor ilusión trascendental posible" (Kant, 2000, p. 508). Así pues, la prueba cosmológica:

Se basa en la experiencia, lo cual le permite ofrecer de sí misma una imagen distinta del argumento ontológico [...]. Pero la demostración cosmológica no se sirve de esta experiencia más que para un único paso, el requerido para llegar a un ser necesario. Sobre cuáles sean las propiedades de éste, el argumento empírico no puede informarnos [...]. Toda la fuerza demostrativa contenida en el llamado argumento cosmológico no consiste pues, en otra cosa que en el argumento ontológico, construido con meros conceptos; la supuesta experiencia es superflua. (Kant, 2000, pp. 508-509)

Kant afirma que la prueba cosmológica aparenta partir de la experiencia. Pero este razonamiento abusa de la categoría de causalidad pues sólo se pueden afirmar causas dentro de los límites de la experiencia posible. Y nadie puede asegurar que la causa necesaria de lo contingente sea Dios. Puede ser la naturaleza, por ejemplo, y ella se bastaría sola. O puede ser el Dios del panteísmo, que es totalidad eterna e infinita de la naturaleza. La prueba cosmológica termina cayendo en el mismo defecto de la ontológica: afirma a Dios como necesario, pero sin evidencia experiencial de ello, sólo por simple juego lógico indebido. La prueba cosmológica "Puede conducirnos al concepto de necesidad absoluta, pero no demostrar tal necesidad en una cosa determinada" (Kant, 2000, p. 509).

La prueba físicoteológica (o teleológica), correspondiente a la quinta vía de Santo Tomás (Orden del mundo), se basa en el orden y el sentido, y desde esa evidencia declara la inteligencia del creador, para darle comprensibilidad a las cosas en el mundo. Santo Tomás acentúa la orientación finalística del acto creador:

La quinta se deduce a partir del ordenamiento de las cosas. Pues vemos que hay cosas que no tienen conocimiento, como son los cuerpos naturales, y que obran por un fin. Esto se puede comprobar observando cómo siempre o a menudo obran igual para conseguir lo mejor. De donde se deduce que, para alcanzar su objetivo, no obran al azar, sino 
intencionadamente. Las cosas que no tienen conocimiento no tienden al fin sin ser dirigidas por alguien con conocimiento e inteligencia, como la flecha por el arquero. Por lo tanto, hay alguien inteligente por el que todas las cosas son dirigidas al fin. Le llamamos Dios. (De Aquino, S.T., 2001, pp. 112-113)

Kant enfrentará la prueba del orden, la prueba del finalismo creacional, la prueba del autor inteligente del orden natural que conduce todo a su fin, en la sección sexta bajo el epígrafe "Imposibilidad de la demostración físicoteológica". Si la prueba cosmológica nos podía acercar a la construcción de la teología natural, la bondad de esta prueba hará afirmar a Kant que "Merece ser mencionada siempre con respeto. Es la más antigua, la más clara y la más apropiada a la razón ordinaria" (Kant, 2000, p. 519). Antes de este comentario laudatorio había enunciado su pretensión, pero también su insuperable inconsistencia: "La idea trascendental de un primer ser necesario y omnisuficiente es tan inmensamente grande, tan superior a todo lo empírico - siempre condicionado-, que jamás podemos reunir en la experiencia materia suficiente para llenar este concepto" (Kant, 2000, p. 517).

Kant enuncia que la prueba se funda en el hecho de que el mundo muestra por todas partes indicios de un orden que señala un propósito. Orden realizado por una sabiduría, que dada la infinita variedad y multiplicidad de los seres y procesos naturales, no reside en las distintas cosas del mundo. Existiría entonces una unidad causal, "una causa sublime y sabia (o varias) que ha de ser la causa del mundo". La percepción del orden y la belleza del mundo no está, ni puede estar, asociada al experimentar las cosas, los fenómenos, en las categorías espacio-temporales propias de la estética trascendental. Esa percepción global y totalizante se sirve de un proceso de pensamiento analógico. La base de esta analogía, concuerda Kant, asociaría los productos naturales y los productos del ingenio humano (casas, barcos, relojes). De tal argumentación analógica juzgará que "No podemos hallar un procedimiento más seguro que el de la analogía con esos productos dotados de finalidad" (Kant, 2000, p. 521). Ese modelo de asociación analógica supliría la imposibilidad de verificar una experiencia espaciotemporal, puntual, histórica, del fenómeno creacional.

La insuficiencia de la prueba radica en las mismas objeciones hechas a las anteriores, veamos la exposición del tejido de observaciones críticas de Kant:

El paso a la totalidad absoluta es enteramente imposible por vía empírica $[\ldots]$ Tras haber avanzado un buen trecho sobre el suelo de la naturaleza y de la experiencia, abandonan de pronto ese suelo y se pasan al 
reino de las meras posibilidades, donde esperan aproximarse, volando con las alas de las ideas, a lo que se había sustraído a toda su investigación empírica [...] Extienden el concepto ya determinado (a cuya posesión han llegado sin saber cómo) al campo entero de la creación, y explican empíricamente un ideal que no es más que un producto de la razón pura. (Kant, 2000, pp. 522-523)

La existencia de esos seres bien organizados, la armonía constatable en las relaciones naturales, señalan la idea de una inteligencia perfectísima, una providencia máxima y omnipotente que ha impreso finalidades a todo lo creado. Kant criticará esta prueba al sentenciar que, a lo más que puede llegar es a afirmar un ordenador inteligente de conjuntos materiales, un arquitecto del mundo, "que estaría siempre muy condicionado por la aptitud de la materia que trabajara" (Kant, 2000, p 521). Nada dice de un ser creador. Además, caemos en el mismo defecto de la prueba ontológica: se remonta desde lo ordenado de la naturaleza, bajo la contingencia de los seres, hacia una idea de ser supremo, punto inicial que rompe el absurdo de la cadena infinita de las causas contingentes en una necesaria, siendo esta causa el ser creador y omnipotente; del cual no tenemos evidencia de su operación intelectual y creadora, hundiéndose en la misma insuficiencia de la prueba cosmológica con su correspondiente referencia, indebida, a la causa ontológica: "A la hora de demostrar la existencia de un único ser originario como ens summum, la prueba fisicoteológica se basa en la cosmológica y ésta, a su vez, en la ontológica" (Kant, 2000, p. 523).

Dios es idea en sí, Absoluto, noúmeno, incondicionado, ser único infinito, no es un objeto de investigación desde los requisitos del conocer científico. Pero la razón humana, subjetivamente, lo supone como un ser necesario, como un ser supremo que "se queda, pues, en un mero ideal, aunque sea un ideal inobjetable, un concepto que culmina y corona el entero conocimiento humano, y cuya realidad objetiva no puede demostrarse por este camino, pero tampoco refutarse" (Kant, 2000, p. 530). La idea de Dios aparece entonces como horizonte supremo de síntesis del conocer, síntesis de todos los conocimientos reales, pero ello provoca en la razón teórica contradicciones e inconsistencias. El mundo y la razón teórica se independizan de Dios para preservar la distancia debida entre creador y creatura. Respecto de las ideas examinadas en la Dialéctica, concluye Kant: "Esas ideas no han de aceptarse en sí mismas, sino simplemente como realidad de un esquema del principio regulador que unifica sistemáticamente todo el conocimiento de la naturaleza" (Kant, 2000, p. 549). 
El alegato contra la metafísica no es la negación plena de la religión. El poder negativo de la filosofía crítica de Kant ha servido, no para afirmar, sino para proponer los límites y así evitar los errores (Kant, 2000, p. 572). Entonces, lo que se ha invalidado es la pretensión del conocimiento metafísico, la aspiración a generar informaciones, generalizaciones y certezas de carácter científico, pues sus objetos escapan de la constatación sintética, fenoménica, espacio-temporal, que son básicas para la constitución del conocer científico.

\section{Los postulados en la Crítica de la razón práctica}

En este apartado, se quiere abordar la continuación de la reflexión kantiana acerca de la idea de Dios en su segunda gran obra sistemática. Dado que el autor acomete el segundo gran plano de estudio filosófico, lo pertinente al mundo de la libertad, nos permitimos un rodeo por el contexto de formulación crítica de la ética, para reconocer entonces lo pertinente a la dimensión de los postulados de la razón pura práctica en donde reconoceremos el concepto de "Dios" y la consecuente oferta de un teísmo moral, de una teología moral distinta a la examinada como teología tracendental.

La segunda crítica empieza donde Kant dejó el tema de la primera. Es decir, el uso práctico de la razón pura, trata de aquello que escapa al control fenoméni$\mathrm{co}$, a los conocimientos exactos y necesarios del mundo natural. En esta segunda crítica (Kritik der Practische Vernunft), o Crítica de la razón (pura) práctica, de 1788, responderá a la pregunta ¿qué debemos hacer?, y su resultado es la fundación racional del saber moral. Entre la primera y la segunda crítica, Kant escribió y publicó la Fundamentación de la metafísica de las costumbres en 1785, que emprende el estudio de lo ético desde el conocimiento vulgar hasta concluir con una razón práctica.

La metafísica tradicional desarrollaba los noúmenos (Alma, Mundo y Dios) como objetos desde los cuales se enunciaban verdades irrestrictas, evidentes e incuestionables. Pero en Kant pierden legitimidad como conocimiento científico pues la ciencia sólo trata de lo experiencial, lo fenoménico, lo percibible en el espacio y el tiempo, lo susceptible de ser transformado en una fórmula que modifica las entidades naturales de forma causal. Lo metafísico no es pertinencia del conocimiento científico.

Pero los hombres, según el decir de Gadamer, “[...] somos ciudadano de dos mundos. Estamos situados no sólo en el lugar físico, sino también en el 'lugar trascendental' de la libertad" (Gadamer, 2001, p. 182). Vive situaciones que no 
entran en las dependencias causales de los hechos naturales. El hombre es más que una cosa al lado de otras cosas: su conducta escapa de los determinismos físico-naturales. El hombre tiene valor en sí mismo, es el ser radicalmente libre, vive decidiendo acerca de lo bueno y lo malo, acerca de las relaciones sociales y políticas, y guarda una esperanza de plenitud. Además del mundo natural, objetivo, fenoménico, necesario, explicable (científico); compartimos un segundo mundo, el mundo de la libertad. Tal mundo de la libertad, o mundo inteligible, es el mundo de la ética, la política y la religión. Mundo de relaciones humanas prácticas, que exige al hombre autónomo establecer normas, deberes e imperativos que hagan posible que todo ser humano sea respetado como tal y alcance el mayor de los bienes.

Kant, en el mundo de la libertad, opera nuevamente un giro copernicano en el pensamiento. Antes, el concepto ético de bien -lo esencial y absolutamente bueno es...- determinaba, cuál era el deber -luego, si lo bueno es...yo debo...-. Y así, consecuentemente, lo metafísico - a priori universal abstracto- fundaba lo moral -a posteriori, normativo, concreto y personal-. Con el criticismo kantiano finaliza la consideración de la conducta orientada por una finalidad extrínseca al sujeto. En Kant la libertad es postulada como fundamento; será la autonomía de la voluntad, el deber en cuanto tal, enunciado, a través de una fórmula, el imperativo categórico, el que determine el bien; y además, será la reflexión de la razón en su uso práctico, el mundo de la libertad, el saber moral, lo que defina a la metafísica. Inscrito el horizonte moral del hombre bajo la enseña de la autonomía, subsecuentemente, la religión y el concepto de Dios como idea regulativa, ganará en densidad racional e independencia personal, dando un paso adelante por encima de dogmatismos o gimnásticas pseudocientíficas.

En la Crítica de la razón práctica (1788), la pertenencia del hombre al mundo inteligible es la condición de su libertad. La libertad se establece en el yo cognoscente y pensante, sobreponiéndose a las determinaciones materiales y sensibles, más allá de lo biológico y simplemente psicológico, alcanzando absolutez y universalidad. La libertad es el primer postulado de la razón práctica, la condición de la vida moral. "[Se deriva] de la necesaria presuposición de la independencia del mundo sensible y de la facultad de la determinación de su voluntad, según la ley de un mundo inteligible" (Kant, 1983, p. 183).

Para fundar no dogmática, ni material, ni exteriormente la moral, Kant propondrá que el punto de partida, ya no es el bien (externo e impropio) al que tendemos desde nuestros sentidos, como seres naturales inmersos en un mundo material, regido por regularidades necesarias. Para Kant el deber no es consecuencia del bien. La moralidad de los actos no se puede fundar nunca sobre la 
materialidad o la exterioridad; es decir, sobre el objeto del acto moral. Nuevamente debemos buscar los fundamentos puros, formales, que hagan factible un acto bueno sin el determinismo ni de las peculiaridades culturales, ni de las limitaciones personales del sujeto; ni de la fuerza del placer o el disgusto que emana del objeto deseado.

¿Cuál es el "a priori" del mundo de la libertad? ¿Qué es lo universal, neutral, que está en el fondo del pensar ético, sin ser ni sintético-empírico -a posteriori dinámico, pero particular-, ni meramente analítico -a priori universal, pero estático-? Partiendo del proceso ético ascensional de la Fundamentación de la metafísica de las costumbres, el agente correspondiente del sujeto de apercepción trascendental de la razón pura teórica, en el uso práctico, lo constituye la buena voluntad: "Ni en el mundo, ni, en general, tampoco fuera del mundo, es posible pensar nada que pueda considerarse como bueno sin restricción, a no ser tan sólo una buena voluntad" (Kant, 1983, p. 21).

¿Qué hace buena a la buena voluntad? Ni las obras concretas, ni los fines bien justificados, ni los éxitos alcanzados, ni los ideales heroicos, fueren de la naturaleza que fueran. La suma bondad y la reverencia que se tiene a Dios, tampoco podría ser, por mera transmisión cultual o costumbre social, o comunicación ideológica, un punto de vista certero. ¿Qué conforma el principio objetivo de la moralidad? ¿Qué es aquello que va más allá de las experiencias concretas e instantáneas?: "La buena voluntad no es buena por lo que efectúe o realice, no es buena por su adecuación para alcanzar algún fin que nos hayamos propuesto; es buena sólo por el querer, es decir, es buena en sí misma" (Kant, 1983, p. 21).

La voluntad escapa de las trampas sensibles o materiales de las dependencias heterónomas. La voluntad resulta ser el espacio impoluto que posibilita la autonomía, es buena en sí misma y por ello es la fuente de la razón pura práctica, del saber moral. En la Crítica de la razón práctica difinirá: “La autonomía de la voluntad es el único principio de todas las leyes morales y de los deberes conformes a ellas" (Kant, 1983, p. 114). Desde la buena voluntad se deriva todo el andamiaje del juicio ético, de las leyes morales y desde ellas, de los deberes.

El producto permanente de la voluntad es el deber. Lo bueno es el deber. El fondo común a todas las acciones éticas ajenas a las inclinaciones sensibles y materiales, es el deber. La acción es buena en la medida en que es realizada por puro respeto del deber. Esa es la pureza en la operación de la voluntad, no basta con hacer las cosas por legalismo (pues una ley positiva está en la exterioridad), o porque el deber coincide con mi propio agrado (porque entonces sería un gusto o placer personal), sino porque las acciones forzadas por el deber se realizan sin 
depender, ni de presiones externas, ni de sentimientos internos. El deber en sí, el deber por el deber es, como afirmamos arriba, lo más puramente objetivo que participa en el saber moral. Recordemos la célebre exaltación que el maestro de Köenigsberg hiciera de esta piedra angular de la moralidad:

¡Deber! Oh nombre sublime y grande, que no encierras en ti nada que sea grato, nada que halague...pero que por otra parte, no amenazas con nada que despierte aversión natural en el ánimo, tú que sólo exiges una ley que fuerza su entrada en las conciencias $y$, sin embargo, quiérase o no, se hace venerar (aunque no siempre cumplir), silenciando el coro de las inclinaciones...¿Dónde se halla la raíz de tu noble ascendencia, que rechaza orgullosamente todo parentesco con las inclinaciones, esa raíz, de la cual es condición necesaria que proceda aquel valor que sólo los hombres pueden darse a sí mismos?. (Kant, 1983, p. 151)

El origen del deber, la "raíz de tu noble ascendencia", sería: "la personalidad, es decir, la libertad e independencia del mecanismo de toda la naturaleza, considerada esa libertad al mismo tiempo como una facultad de un ser que está sometido a leyes puras prácticas peculiares, es decir, dadas por su propia razón" (Kant, 1983, p. 151). El deber surge del sujeto racional, o sea, del hombre diferenciado de la naturaleza, del hombre en cuanto ser razonable, digno y respetable que lucha contra las tendencias naturales y por eso es capaz de imponerse leyes morales. En orden a la aceptación práctica de la idea de Dios, es importante hacer notar que la raíz moral de tal asunción no es ni la revelación, ni la tradición ni las "auctoritas". Es la libertad. El respeto al ser humano constituye entonces el principio subjetivo de la moralidad.

El hombre es entonces, voluntad (pura y autónoma) que permite superar lo sensorial y asumir lo racional. Se hace sujeto de obligaciones, porque puede negarse a las obligaciones, a diferencia de los objetos y las cosas del mundo sensible, perpetuamente sometidos a la necesidad, a las incontrovertibles causalidades físico-naturales. Si debo, es que puedo, luego existe libertad. Gracias a la libertad, lo nouménico, lo suprasensible, lo inteligible se hace presente en el mundo por acción de la persona libre y racional que se impone el deber.

La dignidad del ser humano se postula como absoluto, como fin en sí mismo, como realidad imposible de cosificar o reducir a una simple relación utilitaria. Adela Cortina nos reseña de Kant que: “El deber por el deber, significa, a nuestro juicio, que lo moral es obrar de acuerdo con los dictados de mi propia conciencia, puesto que se trata de respetar mi decisión de proteger la dignidad humana" (Cortina \& Martínez, 2001, p. 72). 
El hombre es al tiempo naturaleza sensible y razón. Si fuera pura razón las acciones del hombre serían necesarias y espontáneamente santas. Si fuera sólo sensibilidad no tendría opciones, reaccionaría con el automatismo y la plena heteronomía instintual de los animales. Pero el hombre obra libremente, en Kant moralidad y libertad son idénticas: la libertad establece la posibilidad de actuar no simplemente determinado por lo sensible o lo ajeno a sí mismo. Libertad es esencialmente autonomía. Todos los seres humanos tenemos la experiencia de actuar por encima de las inclinaciones naturales, porque la razón nos propone el cumplimiento de un conjunto de reglas, porque nuestra experiencia y nuestra historia nos proporcionan unos mandatos a los que cedemos sin restricción ni condición alguna. La objetividad, la autonomía, el ejercicio libre de la moralidad hacen parte de la naturaleza humana. Kant, en La religión dentro de los límites de la mera razón conceptuará:

Por naturaleza del hombre se entenderá solo el fundamento subjetivo del uso de su libertad en general (bajo leyes morales objetivas), que precede a todo hecho que se presenta a los sentidos, dondequiera que resida este fundamento. Pero este fundamento subjetivo a su vez tiene siempre que ser él mismo un acto de la libertad. (Kant, 1981, p. 31)

Por la sujeción al deber es que nos reconocemos como criaturas racionales no definidas ni limitadas por las exigencias y las presiones de la naturaleza. El cumplimiento del deber es aquello incondicionado en el que coincidimos los hombres cuando decidimos racionalmente. El deber es aquello que nos doblega a reconocer en el otro, un sujeto de derechos al cual debo respetar y con el cual también tengo deberes. El deber es la fuerza que nos permite hacer al otro lo que a él le gustaría que le hicieran.

El Supremo Bien en Kant es requerido por el deber. Lo puntual, circunstancial y concreto en nuestro diario vivir, aspira alcanzar un trascendente moral que jalona el perfeccionamiento, que es regulación para una plenificación. Lo fáctico se mueve hacia lo incondicionado, lo mínimo hacia lo máximo, lo conveniente y contingente hacia lo Absoluto. En término racionales, estamos ante la unión de dos grandes objetos, la virtud y la felicidad:

En cuanto la virtud y la felicidad conjuntamente constituyen la posesión del supremo bien en una persona, y en cuanto además, estando la felicidad repartida exactamente en proporción a la moralidad (como valor de la persona y de su dignidad para ser feliz), constituyen ambas el supremo bien de un mundo posible, significa esto el completo, el acabado bien. (Kant, 1983, p. 168) 
El principio del deber auspicia una completud de la acción respecto al mandato moral. Nadie asume un deber para medio cumplirlo o ignorarlo. Ello repugna a la razón. Así, primero que todo, la vida moral exige una perfección, una conformidad plena entre nuestras intenciones como seres particulares, con el deber. La felicidad es una aspiración imbricada en la realidad de la dignidad personal, puesta bajo las definiciones de la perfección moral. Su carácter en ocasiones meramente emocional obliga a que su disposición esté bajo la regencia de la virtud, de la moralidad, del deber, como principio regulador de la experiencia. Pero el supremo bien solo se constataría como unidad sintética de virtud y felicidad. El supremo bien llega a ser, en el marco de la razón práctica, "un concepto sintético a priori, cuya posibilidad debe ser deducida trascendentalmente" (Rabade, López \& Pesquero, 1988, p. 78). Esto es, alcanzar en la práctica, en el obrar mismo, el mayor grado de virtud.

Desde el fundamento de la ley moral, asumimos el ideal de santidad. la cual se define como "la adecuación completa de la voluntad a la ley moral", perfección de la que no es capaz, en ningún momento de su existencia, ningún ser racional del mundo sensible. Pero es un dinamismo de actuación tal que la santidad, más que una heroica curiosidad de las acciones de algunos individuos excéntricos, fuera del común, es "exigida como prácticamente necesaria, no puede ser hallada más que en un progreso que va al infinito hacia aquella completa adecuación". Esta realidad que impele una dinámica práctica a todo hombre no sería ajena a su naturaleza, a su disposición genérica pues "es necesario admitir tal progresión práctica como el objeto real de nuestra voluntad" (Kant, 1983, p. 176).

Todo individuo conectado con su materialidad, por sus leyes físicas, al devenir también sensible, falible y perecedero en la realidad física, jamás puede en su corto tiempo de vida agotar ese deseo irrestricto de satisfacción de la perfección. Para tal horizonte de grandeza, para tal dinámica de "progreso infinito", no alcanza ni este cuerpo, ni esta vida natural, ni estos tiempos mundanos. No obstante, como ya señalamos arriba, la razón práctica obliga a perseguir tal perfección, demanda ese jalonamiento hacia lo ilímite, es tal esperanza el objeto de la voluntad de todo humano. Por ello es necesario postular la inmortalidad del alma: "este progreso infinito es, empero, sólo posible, bajo el supuesto de una existencia y personalidad duradera en lo infinito del mismo ser racional". El alma inmortal es el segundo postulado por el cual, dada la existencia y la persistencia indefinida de la persona, esta puede alcanzar la plenitud en el buen obrar: "Así pues, el bien supremo es prácticamente sólo posible bajo el supuesto de la inmortalidad del alma; por consiguiente, ésta, como ligada inseparablemente con la ley moral, es un postulado de la razón pura práctica" (Kant, 1983, p. 176). 
Ahora bien, la perfección de la virtud nos lleva en la santidad al premio de tal esfuerzo: el Supremo Bien, enlace de la virtud y la felicidad, postulando la inmortalidad del alma como necesario para el progreso moral. La vivencia de una moral autónoma regida por el imperativo categórico acerca la subjetividad a la plenitud de la virtud. Esta ley moral "tiene que conducir también a la posibilidad del segundo elemento del bien supremo, a saber, la felicidad adecuada a aquella moralidad" (Kant, 1983, p. 177).

¿Qué es la felicidad?:

"La felicidad es el estado de un ser racional en el mundo, al cual, en el conjunto de su existencia, le va todo según su deseo y voluntad concordancia de la naturaleza con el fin total que él persigue y también con el fundamento esencial de determinación de su voluntad [...]." (Kant, 1983, p. 177)

Kant tenía plena conciencia de que forjar el destino y la meta del hombre centrados en el deber, bajo los dictámenes de la ley moral, no sería tarea ni fácil, ni popular, ni de evidentes resultados gratificantes. Actuar según la ley moral exige renunciar a comodidades, sacrificar y reprimir demasiados impulsos, negar o desplazar los reclamos del instinto. Kant conoce que los sujetos empeñados en la rectitud de su actuar moral, como afirma Tejedor de la Iglesia (2014), "no se ven recompensados con el disfrute de la felicidad [...]; la persona más feliz no es siempre la que ha obrado más rectamente" (Kant, 1983, p. 83).

¿Se oponen felicidad y moralidad? No necesariamente. Si se entiende felicidad desde el reducido margen de definición de la satisfacción de los impulsos, no sería necesario ni siquiera ser seres racionales, pues para ello bastaría con funcionar instintualmente y nada más. El ser humano, como es evidentemente constatable en todo el discurso kantiano, es fundamentalmente racional, práctico e intersubjetivo; y por tal razón circunscribe las demandas de la felicidad a la ejemplaridad de los actos decididos por la ley moral que desembocan en la construcción de la comunidad. Ser plenos, ser felices, es ser morales, ser autónomos, ser libres y con ello, hacer felices a los otros, levantar una sociedad que experimente la felicidad general. Volviendo a la Crítica de la razón pura se nos define lo que tendría que resultar un goce proporcional de moralidad y felicidad: "La felicidad va ligada a la moralidad y es proporcional a ésta, ya que la libertad misma, en parte impulsada por las leyes morales y en parte restringida por ellas, sería la causa de la felicidad general" (Kant, 2000, p. 633). 
Pero por mera voluntad íntima y solitaria, no podemos acceder a la felicidad. La felicidad es el gozo por la consecución de todos los bienes posibles, de todos los fines posibles, en el respeto incondicionado del deber, uniendo decisión personal virtuosa y conducta de la naturaleza. Mas la felicidad no la puede conseguir el hombre ni por sí sólo, ni en este espacio, pues su lado biológico, su dimensión mundana y natural, el choque permanente y frustrante con los seres que se rigen determinados naturalmente, siempre será impedimento para realizar totalmente y de manera permanente el gozo de la felicidad. Se requiere entonces resolver quién hace posible la coincidencia entre la ley moral y felicidad para la consecución del supremo bien. Postulada la libertad y la inmortalidad del alma, y asociado el supremo bien en la conjugación de virtud y felicidad, en las dinámicas de la razón enfrentada a los retos de la vida práctica, llegamos al tercer postulado:

Así pues, la causa suprema de la naturaleza, en cuanto ella ha de ser presupuesta para el supremo bien, es un ser que por razón y voluntad es la causa (por consiguiente, el autor) de la naturaleza, es decir Dios. Por consiguiente, el postulado de la posibilidad del bien supremo derivado (el mejor del mundo) es al mismo tiempo el postulado de la realidad de un bien supremo originario, esto es, de la existencia de Dios. [...] La posibilidad de este bien supremo, lo cual no ocurriendo más que bajo la condición de la existencia de Dios, enlaza inseparablemente la presunción del mismo con el deber, es decir, que es moralmente necesario admitir la existencia de Dios. (Kant, 1983, p. 178)

La conciencia, atendiendo a la dimensión de absolutez del Supremo Bien postula entonces la existencia de Dios en orden a darle completud a la búsqueda de esa unidad del máximo bien. Dios es un postulado moralmente necesario: hace posible como bien supremo originario tomar decisiones y existir moralmente para hacer el mejor de los mundos.

De otra parte y seguido de esta conclusión, Kant juzga como importante la oferta de salvación del cristianismo, que representa la adopción de una ley moral que posibilita un ejercicio racional de la religión. En el cristianismo se persigue el supremo bien cimentándose la acción en la moralidad y prospectando en la esperanza el gozo infinito de la felicidad total, la bienaventuranza. Kant afirma:

La santidad de las costumbres se les muestra ya en esta vida como guía; pero el bien proporcionado a ella, la bienaventuranza, se representa sólo como asequible en una eternidad. [...] La bienaventuranza, bajo el nombre de la felicidad, no puede ser alcanzada en este mundo (en 
cuanto que depende de nuestra facultad), y por eso tan sólo se hace objeto de la esperanza. (Kant, 1983, p. 180)

Contrario a lo examinado en la dialéctica trascendental de la razón pura teórica, que desechaba el conocimiento de Dios por ser un paralogismo, una ilusión trascendental, un uso indebido dada la no fenomenidad del objeto "Dios"; en la Crítica a la Razón pura práctica, la postulación, que no demostración, es un requisito de la Razón para alcanzar el sentido del obrar humano.

Kant afirma entonces que, en el horizonte de crecimiento moral del ser humano, en el mundo regulado por la razón práctica, necesitamos postular a Dios para darle coherencia a la búsqueda temporal y eterna de la perfección del deber. De eso trata la fe. Por ello lo religioso no puede ser conocimiento científico estricto, porque perdería su carácter libre e íntimo. La existencia de Dios constituye la condición necesaria de la moralidad. En Kant lo religioso no es superior y anterior a lo moral. Todo lo contrario: lo moral es primero y es condición de la práctica religiosa.

Para un desempeño moral humanamente plenificante en la vida, es necesario y razonable creer en Dios, que hace real el Supremo Bien en cada persona. $Y$ creer es un acto de la voluntad, íntimo, personal, libre, es decir "yo quiero": "La persona honesta puede decir: quiero que exista un Dios, que mi duración sea infinita [...]. Me adhiero firmemente a ello y no me dejo arrebatar mi creencia..." (Kant, 1983, p. 190). Nos acercamos entonces a la consideración de la religión, en la perspectiva crítica racional de Kant.

\section{Religión revelada y religión natural, La religión dentro de los límites de la mera razón}

La religión dentro de los límites de la mera razón (Kant, 1981), como bien se resume en su nombre, es la obra por la que “[...] Kant quería poner los fundamentos de una religión en los límites de la simple razón, siguiendo el espíritu deísta de la ilustración, pero fundando esta conclusión religiosa o teológica sobre la racionalidad del obrar moral" (Grondin, 2000, p. 82). Esta obra, en ocasiones ignorada, o por lo menos no muy popular entre los académicos, según Grondin "es la continuación directa de la Vernunftkritik [respondería] en cuanto la tercera pregunta¿qué me está permitido esperar? [...]" (Grondin, 2000, p. 84). Esta obra sumaría argumentos a las dos críticas para establecer una justificación de la fe racional y práctica 
acerca de la consideración humana de Dios. Grondin sugiere que, habiéndose tratado el tema de Dios en ambas críticas, La religión en los límites de la mera razón deviene como la tercera crítica, en la cual concluye lo estudiado anteriormente.

Kant, otrora deudor del discurso rousseauniano acerca de la religión natural, fundándose como buen ilustrado en la autonomía absoluta de la razón, establece en clara oposición al planteamiento optimista del ginebrino, una base de malignidad al surgimiento de lo religioso. Su primer capítulo se llama, sugestivamente, "De la inhabitación del principio malo al lado del bueno o sobre el mal radical en la naturaleza humana". El hombre, universalmente considerado, experimenta la fragilidad, la impureza y la malignidad que son los tres grados diferentes de "propensión natural del hombre al mal" (Kant, 1981, p. 38). El mal no es pura cuestión del contacto sensible del hombre con la realidad. Ni tampoco una corrupción de la razón en el proceso moral de toma de decisiones e imposición de máximas en las personas. El mal que hace parte de la esencia natural de lo humano es una inversión de motivos al orientar la ley moral que todos manifestamos. Kant explica entonces:

Consiguientemente, el hombre (incluso el mejor) es malo solamente por cuanto invierte el orden moral de los motivos al acogerlos en su máxima: ciertamente acoge en ella la ley moral junto a la del amor a sí mismo hace de los motivos del amor a sí mismo y de las inclinaciones de este la condición del seguimiento de la ley moral, cuando es más bien esta última la que, como condición suprema de la satisfacción de lo primero, debería ser acogida como motivo único en la máxima universal del albedrío [...]. (Kant, 1981, p. 46)

Esta consideración acerca de la maldad humana como nacida de la orientación hacia sí mismo oficiará como punto de partida para enunciar la necesidad práctica del ejercicio religioso, en la perspectiva de lo racional-moral. En ocasiones, la razón juzga que ese mal intrínseco es imposible de cambiar, de mudar, por las solas fuerzas del sujeto. Esa imposibilidad natural a seguir la ley moral encuentra una oferta que seduce a la razón: las ideas religiosas impuras inculcan que es Dios mismo quien realiza el principio de felicidad "por condición suprema de sus mandamientos" (Kant, 1981, p. 60). En otras palabras, Dios resuelve el problema de enfrentar la conversión del amor a sí mismo como absoluto comportamental y desde afuera, legisla para que sumisamente el hombre y su mal se encaminen hacia las sendas del bien. Dios así concebido sería un externo, material, legislador, que no permite el libre albedrío e ignora las posibilidades racionales y prácticas de su creatura. 
Kant explica que son dos los tipos de religión:

“La Religión de la petición de favor (del mero culto) y la Religión moral, esto es: la Religión de la buena conducta de vida. Con arreglo a la primera el hombre se adula pensando que Dios puede hacerlo eternamente dichoso sin que él tenga necesidad de hacerse un hombre mejor. En cambio, según la Religión moral (tal es, entre todas las religiones públicas que ha habido, solo la cristiana) es principio lo que sigue: que cada uno ha de hacer tanto como esté en sus fuerzas para hacerse un hombre mejor." (Kant, 1981, p. 61)

La religión debida a verdades reveladas, aparecida en un momento específico de la historia, con unos estatutos rituales y doctrinales singulares, que se ofrece a los hombres a través de una Escritura de carácter sagrado, que cuenta con unos estamentos cuya autoridad obliga a obrar bien, porque Dios así lo exige, tal religión se denomina revelada o estatutaria. Las religiones de este tipo se encuentran situadas históricamente. Por ello Kant toma distancia, para poder establecer una religión racional nacida de los principios a priori universales, válidos para todos en todos los lugares. En esta religión revelada, estatutaria; se sabe que algo es mandamiento divino para que la acción sea reconocida como deber.

Kant distingue la religión (moral, racional, universal), de las creencias (reveladas, particulares, históricas). Las creencias pertenecerían a los credos de la religión revelada:

"Solo hay una (verdadera) Religión; pero puede haber múltiples modos de creencia. Se puede añadir que en las iglesias diversas, que se separan unas de otras por la diversidad de sus modos de creencia, puede encontrarse sin embargo una y la misma verdadera Religión. Es, pues, más conveniente (como también efectivamente más usual) decir: este hombre es de esta o aquella creencia (judía, mahometana, cristiana, católica, luterana), que decir: es de esta o aquella Religión." (Kant, 1981, p. 109)

La religión natural, racional, moral, sería aquella en la cual se sabe primero que algo es un deber (imperativo categórico, universal y absoluto) para después apreciarlo como mandamiento divino. Libre y autónomamente el hombre ha hecho un acto de fe racional y moral. Así se experimenta la Religión de la buena conducta de vida. La verdadera práctica religiosa es pues, el cumplimiento del deber por el deber. Todos nuestros deberes, elevados al grado de bien universal, 
percibidos en su absolutez, serán acatados como mandamientos divinos. “La Religión es (considerada subjetivamente) el conocimiento de todos nuestros deberes como mandamientos divinos" (Kant, 1981, p. 150). La religión racional no dañaría algo o alguien, no le haría bien a un grupo, a una clase humana, le haría bien a toda la humanidad, respetada como fin en sí mismo. Esta sería una religión universal en donde, bajo la conducción del deber moral que respetaría a cada ser humano como digno, como fin en sí mismo, todas las creencias tendrían que coexistir.

¿Cómo da el hombre el paso legítimo del mal radical al cumplimiento absoluto de la ley moral, a la vivencia del bien? Kant reconoce entonces la función restauradora de humanidad de Cristo el Señor. Aquí se acogen las palabras de Grondin para dar solución a esta demanda de conversión radical:

Se le ha propuesto al género humano un modelo de perfección para darle la fuerza y el coraje necesarios en su conversión al Bien. Este modelo, que corresponde a Cristo, es para Kant el de una humanidad agradable a Dios, es decir, moral. Cristo es para Kant, pues, el arquetipo de la intención moral en toda su pureza. (Grondin, 2010, p. 133)

La obra de todos los hombre buenos que realizan su deber y lo comprenden como mandato divino traería a su vez la restauración social universal. Pero tal obra, la conformación de una comunidad que perseguiría la restauración moral de todos, esa Iglesia, tendría como autor y fuerza no a un ser humano pequeño, limitado y falible. Kant explica, completando ese fundamento individual, racional y moral sugiriendo: "Instituir un pueblo de Dios moral es por lo tanto una obra cuya ejecución no puede esperarse de los hombres, sino solo de Dios mismo" (Kant, 1981, p. 101).

La religión cristiana acercaría el hombre al deber de hacer el bien universalmente, sería en esa medida una religión natural. Es así como, en la dinámica de la praxis moral, se puede hacer real el Reino de Dios en la tierra. Reino de la dignidad de los hombres que son autolegisladores pues por el deber han superado el mal radical. Reino de un respeto tan grande, que ni el mismo Dios perturba la autonomía de cada persona. (González, 2005). Porque el hombre, "fin en sí mismo no puede ser utilizado (solo) como medio, ni por el mismo Dios supremo" (González, 2005, p. 308). El Dios de Kant que corresponde a la religión racional es un Dios moral: "el único santo, el único bienaventurado, el único sabio" (Kant, 1788/1983, p. 182), que posibilita alcanzar el Supremo Bien. 


\section{Referencias}

Cortina, A. \& Martínez, E. (2001). Ética. Barcelona: Akal.

De Aquino, S. T. (2001). Suma de Teología. Madrid: B.A.C.

De Canterbury, S. A. (1077/1998). Proslogion. Madrid: Tecnos.

Gadamer, H.-G.0: (2001). El giro hermenéutico. Madrid: Cátedra.

Gómez, J. (1983). El teísmo moral de Kant. Madrid: Ediciones Cristiandad.

González, J. (2005). El problema de Dios en la filosofía de Kant. Realidad, 104, abriljunio, pp.269-314. En: http://www.uca.edu.sv/filosofia/admin/files/1211842519. pdf. Recuperado: 04/06/2014

Grondin, J. (2000). La actualidad de La religión dentro de los límites de la mera razón de Kant. Ideas y valores, agosto, 113, pp. 80-85. . (2010). La filosofía de la religión. Barcelona: Herder.

Verneaux, R. (1977). Historia de la filosofía moderna. Barcelona: Herder.

Kant, I. (1781/2000). Crítica de la razón pura. Bogotá: Alfaguara. . (1755/1946). Historia natural y teoría de los cielos. Buenos Aires: Lautaro. . (1793/1981). La religión dentro de los límites de la mera razón. Madrid: Alianza. . (1788/1983). Fundamentación de la metafísica de las costumbres. Crítica de la razón práctica. La paz perpetua. México: Porrúa.

Pannenberg, W. (2001). Una historia de la filosofía desde la idea de Dios. Salamanca: Sígueme.

Rabade, S., López, A. \& Pesquero, E. (1988). Kant: Conocimiento y racionalidad. Vol. 2. El uso práctico de la razón. Madrid: Cincel.

Tejedor de la Iglesia, C. (2014). La teología moral en Kant: sobre virtud y felicidad. Factótum, 11, pp.81-87. En: http://www.revistafactotum.com/revista/f_11/articulos/Factotum_11_6_Cesar_Tejedor.pdf. Recuperado: 15/06/2014. 